\title{
Cycloisomerization of acetylenic oximes and hydrazones under gold catalysis: Synthesis and cytotoxic evaluation of isoxazoles and pyrazoles
}

\author{
J C JEYAVEERAN ${ }^{\mathrm{a}}$, CHANDRASEKAR PRAVEEN $^{\mathrm{b}, *}, \mathrm{Y} \mathrm{ARUN}^{\mathrm{c}}$, \\ A A M PRINCE ${ }^{\mathrm{a}}$ and P T PERUMAL ${ }^{\mathrm{c}}$ \\ ${ }^{a}$ Department of Chemistry, Ramakrishna Mission Vivekananda College, Mylapore, Chennai 600 004, India \\ ${ }^{\mathrm{b}}$ Functional Materials Division, Central Electrochemical Research Institute (CSIR laboratory), \\ Karaikudi 630 006, India \\ ${ }^{\mathrm{c}}$ Organic Chemistry Division, Central Leather Research Institute (CSIR laboratory), Adyar, \\ Chennai 600 020, India \\ e-mail: chandrasekar.praveen@gmail.com
}

MS received 16 September 2015; revised 12 October 2015; accepted 20 October 2015

\begin{abstract}
The synthesis of substituted isoxazoles and pyrazoles through a general cycloisomerization methodology has been reported. The capability of gold(III) chloride to promote cycloisomerization of both $\alpha$, $\beta$ acetylenic oximes and $\alpha, \beta$-acetylenic hydrazones is the centrepiece of the strategy. A range of acetylenic precursors were investigated to afford 28 examples of the products with good to excellent chemical yields. Selected compounds were screened for their cytotoxic potential towards COLO320 cancer cell lines. The $\mathrm{IC}_{50}$ values of the tested compounds were in the micromolar range, with the best compound, 5-(6-Methoxy-naphthalen-2-yl)3-phenyl-isoxazole $(\mathbf{3 h})$ displaying an $\mathrm{IC}_{50}$ of $38.9 \mu \mathrm{M}$. For this compound, the crystal structure in complex with Aurora-A kinase was obtained which revealed details of its binding mode within the active site with a free energy of binding $-9.54 \mathrm{kcal} / \mathrm{mol}$.
\end{abstract}

Keywords. Gold catalysis; cycloisomerization; isoxazoles; pyrazoles; cytotoxicity; molecular docking.

\section{Introduction}

Gold catalyzed cyclization of alkynes possessing proximate nucleophiles has emerged as one of the imperative topics in the field of contemporary metal catalysis, since they offer a wide range of biologically significant carboand heterocyclic derivatives. ${ }^{1}$ Our research group for the past few years has been actively engaged in the development and application of gold catalyzed cyclization methodologies for the synthesis of basic heterocycles like indoles, ${ }^{2 \mathrm{a}, \mathrm{b}}$ furans, ${ }^{2 \mathrm{c}}$ quinolines, ${ }^{2 \mathrm{~d}}$ isoxazoles, ${ }^{2 \mathrm{e}}$ carbazoles $^{2 \mathrm{f}}$ and pyranoindolones. ${ }^{2 \mathrm{~g}}$ On the other hand, the heteroaromatic pharmacophore of isoxazoles ${ }^{3 a}$ and pyrazoles $^{3 \mathrm{~b}}$ as depicted in figure 1 exhibits a wide range of biological properties and has led to continued interest in chemical biology and medicinal chemistry. ${ }^{3 \mathrm{c}-\mathrm{j}}$ The most useful synthetic access of isoxazoles includes the $[3+2]$ cycloaddition of alkenes/alkynes with nitrile oxides or the reaction of hydroxyl amine with a three-carbon component. ${ }^{4}$ Typical methods for the synthesis of pyrazoles involve the approaches based either on the condensation of hydrazines with 1,3-dicarbonyl compounds

*For correspondence and their 1,3-dielectrophilic equivalents including $\alpha, \beta$ unsaturated aldehydes and ketones or on the intermolecular 1,3-dipolar cycloaddition of diazoalkanes and nitrilimines with alkenes/alkynes. ${ }^{5}$ The synthetic scope of the aforementioned protocols is limited by strong reaction conditions, high temperature, poor reactivity and lack of regioselectivity. In the context of heterocycle synthesis by $\pi$-Lewis acids, we have already addressed this problem by employing $\mathrm{AuCl}_{3}$ as an effective catalyst for the cyclization of $\alpha, \beta$-acetylenic oximes leading to isoxazoles. ${ }^{2 \mathrm{e}}$ As an extension of this methodology, we investigated the scope of related $\alpha, \beta$-acetylenic hydrazones for the synthesis of pyrazoles. Following our previous communication concerning the synthesis of isoxazoles, we report herein a comprehensive study which includes the cyclization of $\alpha, \beta$-acetylenic hydrazones leading to pyrazoles, their cytotoxic evaluation and molecular docking studies.

\section{Experimental}

\subsection{Materials and methods}

All commercially available solvents and reagents were used without further purification unless otherwise stated. 


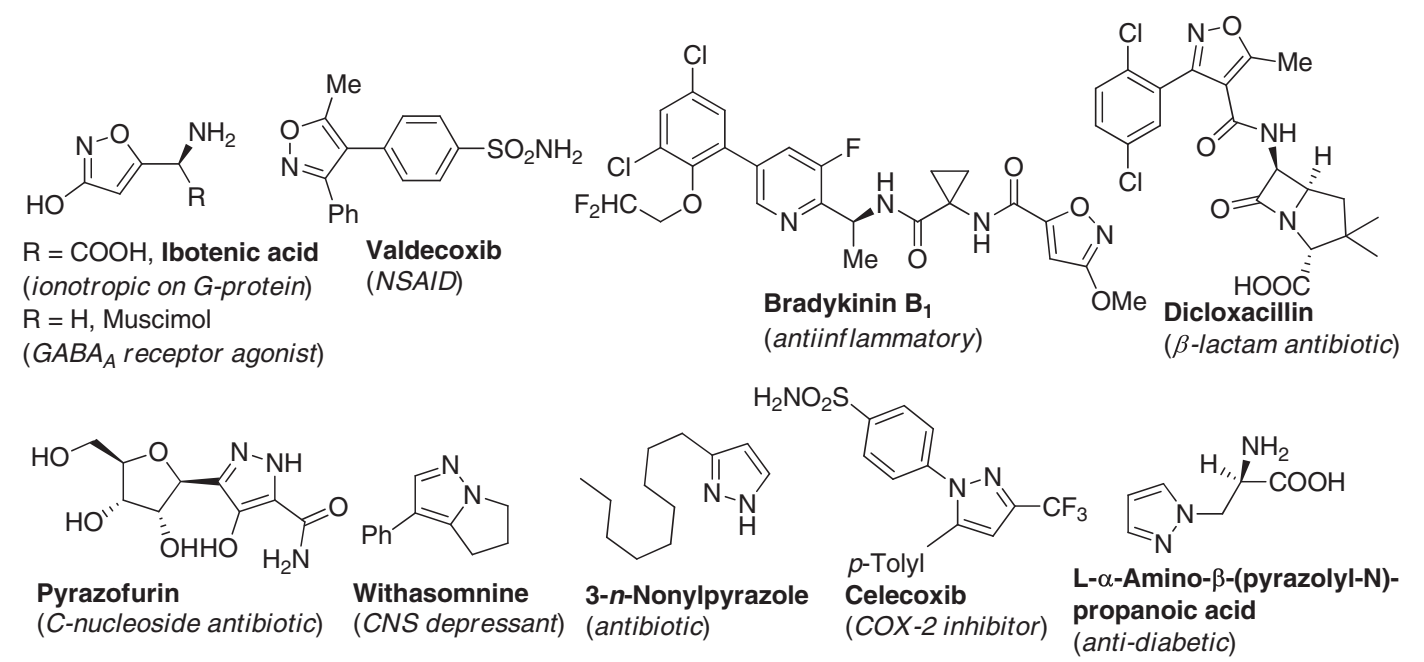

Figure 1. Natural products and clinical drugs containing isoxazole and pyrazole nucleus.

All solvents used in the reactions were distilled for purity. Solutions in organic solvents were dried with anhydrous sodium sulphate. Solvents were evaporated under reduced pressure. The inert atmosphere was created was created by a slight positive pressure (ca. 0.1 psi) of nitrogen. All glassware were dried in an oven prior to use. Melting points were obtained using open capillaries and are uncorrected. Infrared (IR) spectra were recorded on a Perkin-Elmer FTIR spectrophotometer as $\mathrm{KBr}$ pellets for solid compounds and neat sample for liquid compounds. ${ }^{1} \mathrm{H}$ and ${ }^{13} \mathrm{C}$ NMR spectra were obtained in DMSO- $d 6$ and $\mathrm{CDCl}_{3}$ on a JEOL spectrometer at 500 and $125 \mathrm{MHz}$, respectively. Proton chemical shifts $(\delta)$ are relative to tetramethylsilane (TMS, $\delta=0.00$ ) as internal standard and expressed in parts per million. The number of protons $(n)$ for a given resonance was indicated as $n \mathrm{H}$. Spin multiplicities are given as s (singlet), d (doublet), t (triplet), dd (doublet of doublet), dt (doublet of triplet), ddd (doublet of doublet of doublet) and $\mathrm{m}$ (multiplet). Coupling constants $(J)$ are given in hertz. GC-MS spectra were recorded on a Perkin Elmer. Elemental analyses were recorded using a Thermo Finnigan FLASH EA 1112CHN analyzer. All the compounds gave $\mathrm{C}, \mathrm{H}$ and $\mathrm{N}$ analysis within $\pm 0.5 \%$ of the theoretical values. Column chromatography was performed using thick-walled glass columns along with a mixture of petroleum ether and ethyl acetate on silica gel (100-200 mesh, SRL, India). The relative proportions of solvents in chromatography solvent mixtures refer to the volume to volume ratio. Analytical TLC was performed on precoated plastic sheets of silica gel G/UV-254 of $0.2 \mathrm{~mm}$ thickness (Macherey-Nagel, Germany) using analytical grade solvents and visualized with iodine spray (10\% w/w $\mathrm{I}_{2}$ in silica gel), UV light $(\lambda=254$ and $365 \mathrm{~nm})$ and alkaline $\mathrm{KMnO}_{4}$ solution.
COLO320 adenocarcinoma colorectal cancer cell line was obtained from National Institute of Cell Sciences, Pune. Absorption $\left(\lambda_{\max }\right)$ was red at $570 \mathrm{~nm}$ in an ELISA reader. Cytotoxicity of the compounds were statistically analyzed by Duncan multiple range test at $\mathrm{P}=0.05$ with the help of SPSS 11.5 version software package. All computations for molecular docking studies were carried out on a Dell Desktop D510 personal computer (2.4 GHz Pentium 4 processor, Intel, Santa Clara, CA) running Red Hat Enterprise Linux Client release 5.5. The time required for each simulation run was on the

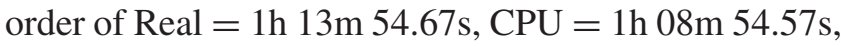
System $=11.75 \mathrm{~s}$ on the Pentium machine.

\subsection{General Procedure for the synthesis of isoxazoles $(3 a-3 r)$}

To a solution of oxime $2(1.0 \mathrm{mmol})$ in dry dichloromethane was added $\mathrm{AuCl}_{3}(0.01 \mathrm{mmol})$ under $\mathrm{N}_{2}$ atmosphere and stirred at the specified time and temperature (table 1). After completion of the reaction as indicated by TLC the reaction mixture was concentrated under reduced pressure and purified by column chromatography over silica gel (100-200 mesh) to afford the pure product of isoxazole 3 .

2.2a 3-Methyl-5-phenyl-isoxazole (3a): Colourless solid; M.p. 76-78 ${ }^{\circ}$; IR (KBr): 3100, 1566, 1157, 1046, 896, $763 \mathrm{~cm}-{ }^{1} .{ }^{1} \mathrm{H}$ NMR $(500 \mathrm{MHz}, \mathrm{CDCl} 3): \delta_{\mathrm{H}} 2.34(\mathrm{~s}$, $3 \mathrm{H},-\mathrm{CH} 3) ; 6.35$ (s, $1 \mathrm{H}$, isoxazolinyl- $H) ; 7.40-7.44(\mathrm{~m}$, $3 \mathrm{H}, \mathrm{Ar}-H) ; 7.74(\mathrm{~d}, 2 \mathrm{H}, J=6.1 \mathrm{~Hz}, \mathrm{Ar}-H) .{ }^{13} \mathrm{C}$ NMR $\left(125 \mathrm{MHz}, \mathrm{CDCl}_{3}\right): \delta_{\mathrm{C}} 11.6,100.2,125.8,127.6,129.0$, 130.0, 160.4, 169.7. MS (ESI): $m / z=159[\mathrm{M}+]$. Anal. Calcd. for $\mathrm{C}_{10} \mathrm{H}_{9} \mathrm{NO}$ : C, 75.45; H, 5.70; N, 8.80\%. Found: C, 75.65; H, 5.67; N, 8.65\%. 
Table 1. Cyclization of oximes 2 to isoxazoles 3

\begin{tabular}{|c|c|c|c|c|c|}
\hline Entry & $\mathrm{R}$ & $\mathrm{R}^{1}$ & $\begin{array}{c}\text { Product } \\
\mathbf{3}^{\mathrm{a}}\end{array}$ & $\begin{array}{l}\text { Time } \\
(\min )\end{array}$ & $\begin{array}{l}\text { Yield } \\
(\%)^{\mathrm{b}}\end{array}$ \\
\hline 1 & $\mathrm{Me}$ & $\mathrm{Ph}$ & $\mathbf{3 a}$ & 10 & 92 \\
\hline 2 & $\mathrm{Ph}$ & $p$-anisyl & $\mathbf{3 b}$ & 10 & 94 \\
\hline 3 & $\mathrm{Ph}$ & $m$-anisyl & $3 c$ & 10 & 91 \\
\hline 4 & $\mathrm{Ph}$ & $p$-tolyl & 3d & 10 & 95 \\
\hline 5 & $\mathrm{Ph}$ & $m$-tolyl & $3 e$ & 10 & 93 \\
\hline 6 & $\mathrm{Ph}$ & $o$-cyanophenyl & $3 f$ & 20 & 82 \\
\hline 7 & $\mathrm{Ph}$ & $p$-fluorophenyl & $3 g$ & 20 & 83 \\
\hline 8 & $\mathrm{Ph}$ & 6-MeO-2-naphthyl & $3 \mathbf{h}$ & 15 & 81 \\
\hline 9 & $p$-tolyl & $\mathrm{Me}$ & $3 \mathbf{i}$ & 10 & 90 \\
\hline 10 & $\mathrm{Ph}$ & 2-hydroxybutyl & $\mathbf{3 j}$ & 25 & 78 \\
\hline 11 & $\mathrm{Ph}$ & $\mathrm{SiPhMe}_{2}$ & $3 \mathbf{k}$ & 30 & $75^{\mathrm{c}}$ \\
\hline 12 & $\mathrm{Ph}$ & $\mathrm{H}$ & 31 & 25 & 80 \\
\hline 13 & $\mathrm{Ph}$ & $\mathrm{Ph}$ & $3 \mathrm{~m}$ & 10 & 93 \\
\hline 14 & $\mathrm{Me}$ & $\mathrm{SiMe}_{3}$ & $3 n$ & 30 & $79^{c}$ \\
\hline 15 & $\mathrm{H}$ & $m$-anisyl & 30 & 10 & 92 \\
\hline 16 & $\mathrm{H}$ & $p$-tolyl & $3 p$ & 10 & 95 \\
\hline 17 & $\mathrm{H}$ & ${ }^{n}$ propyl & $3 q$ & 10 & 89 \\
\hline 18 & $\mathrm{H}$ & ${ }^{\mathrm{n}}$ pentyl & $3 r$ & 10 & 88 \\
\hline
\end{tabular}

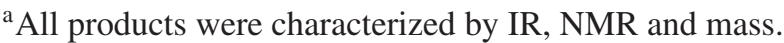

${ }^{\mathrm{b}}$ Isolated yield after column chromatography.

${ }^{c}$ Reaction was performed under reflux.

2.2b 5-(4-Methoxy-phenyl)-3-phenyl-isoxazole (3b): Colourless solid; M.p. $118-120^{\circ}$ C; IR (KBr): 3113 , 2939, 1615, 1501, 1461, 1397, 1252, 1025, $919 \mathrm{~cm}^{-1}$. ${ }^{1} \mathrm{H}$ NMR (500 MHz, CDCl3): $\delta \mathrm{H} 3.84$ (s, 3H, -OCH3); $6.69(\mathrm{~s}, 1 \mathrm{H}$, isoxazolinyl- $H) ; 6.98(\mathrm{~d}, 2 \mathrm{H}, J=9.2 \mathrm{~Hz}$, $\operatorname{Ar}-H) ; 7.46(\mathrm{~d}, 3 \mathrm{H}, J=6.9 \mathrm{~Hz}, \operatorname{Ar}-H) ; 7.76(\mathrm{~d}, 2 \mathrm{H}$, $J=9.1 \mathrm{~Hz}, \operatorname{Ar}-H) ; 7.85(\mathrm{~d}, 2 \mathrm{H}, J=7.6 \mathrm{~Hz}, \operatorname{Ar}-H)$. ${ }^{13} \mathrm{C}$ NMR (125 MHz, CDCl3): $\delta \mathrm{C} 55.4,96.2,114.4$, $125.9,126.8,127.2,128.9,129.0,130.0,161.2,163.0$, 170.4. MS (ESI): $m / z=251[\mathrm{M}+]$. Anal. Calcd. for $\mathrm{C}_{16} \mathrm{H}_{13} \mathrm{NO}_{2}$ : C, 76.48; H, 5.21; N, 5.57\%. Found: C, $76.65 ; \mathrm{H}, 5.17 ; \mathrm{N}, 5.45 \%$.

2.2c 5-(3-Methoxy-phenyl)-3-phenyl-isoxazole (3c): Colourless solid; M.p. 76-78 ${ }^{\circ}$; IR (KBr): 3302, 1604, 1461, 1338, 1223, 1085, $757 \mathrm{~cm}^{-1}$. ${ }^{1} \mathrm{H}$ NMR $(500 \mathrm{MHz}$, $\left.\mathrm{CDCl}_{3}\right): \delta_{\mathrm{H}} 3.86\left(\mathrm{~s}, 3 \mathrm{H},-\mathrm{OCH}_{3}\right) ; 6.81(\mathrm{~s}, 1 \mathrm{H}$, isoxazolinyl- $H) ; 6.98(\mathrm{~d}, 1 \mathrm{H}, J=7.6 \mathrm{~Hz}, \operatorname{Ar}-H) ; 7.37$ $(\mathrm{d}, 1 \mathrm{H}, J=7.6 \mathrm{~Hz}, \operatorname{Ar}-H)$; 7.39-7.47 (m, 5H, Ar- $H$ ); $7.86(\mathrm{dd}, 2 \mathrm{H}, J 1=7.7 \mathrm{~Hz}, J 2=2.7 \mathrm{~Hz}, \mathrm{Ar}-H) \cdot{ }^{13} \mathrm{C}$ NMR $\left(125 \mathrm{MHz}, \mathrm{CDCl}_{3}\right): \delta_{\mathrm{C}} 55.5,97.8,111.0,116.2$, $118.4,125.9,126.9,128.6,129.0,130.1,130.2$, 160.0, 163.0, 170.3. MS (ESI): $m / z=251$ [M+]. Anal. Calcd. for $\mathrm{C}_{16} \mathrm{H}_{13} \mathrm{NO}_{2}: \mathrm{C}, 76.48 ; \mathrm{H}, 5.21 ; \mathrm{N}, 5.57 \%$. Found: $\mathrm{C}$, 76.75; H, 5.17; N, 5.49\%.

2.2d 3-Phenyl-5-p-tolyl-isoxazole (3d): Pink colour solid; M.p. 134- $136^{\circ}$ C; IR (KBr): 3420, 3032, 1601,
1479, 1446, 1300, 1075, 1000, $820 \mathrm{~cm}^{-1} \cdot 1 \mathrm{H} \mathrm{NMR}$ $\left(500 \mathrm{MHz}, \mathrm{CDCl}_{3}\right): \delta_{\mathrm{H}} 2.39\left(\mathrm{~s}, 3 \mathrm{H},-\mathrm{CH}_{3}\right) ; 6.76(\mathrm{~s}, 1 \mathrm{H}$, isoxazolinyl- $H) ; 7.26(\mathrm{~d}, 2 \mathrm{H}, J=7.6 \mathrm{~Hz}, \mathrm{Ar}-H) ; 7.46$ $(\mathrm{d}, 3 \mathrm{H}, J=7.6 \mathrm{~Hz}, \operatorname{Ar}-H) ; 7.71(\mathrm{~d}, 1 \mathrm{H}, J=8.4 \mathrm{~Hz}$, $\operatorname{Ar}-H) ; 7.75(\mathrm{~d}, 1 \mathrm{H}, J=8.4 \mathrm{~Hz}, \operatorname{Ar}-H) ; 7.86(\mathrm{~d}, 2 \mathrm{H}$, $J=7.6 \mathrm{~Hz}, \mathrm{Ar}-H) \cdot{ }^{13} \mathrm{C} \mathrm{NMR}(125 \mathrm{MHz}, \mathrm{CDCl} 3)$ : $\delta_{\mathrm{C}} 21.5,96.9,125.0,125.8,125.9,126.8,129.0,129.7$, 130.0, 140.6, 163.0, 170.6. MS (ESI): $\mathrm{m} / z=235$ $[\mathrm{M}+]$. Anal. Calcd. for $\mathrm{C}_{16} \mathrm{H}_{13} \mathrm{NO}$ : C, 81.68; H, 5.57; $\mathrm{N}, 5.95 \%$. Found: C, 81.75; H, 5.52; N, 6.01\%.

2.2e 3-Phenyl-5-m-tolyl-isoxazole (3e): Colourless solid; M.p. 106- $108^{\circ} \mathrm{C}$; IR (KBr): 3416, 3043, 1600, 1476, 1442, 1295, 1085, 1004, $823 \mathrm{~cm}^{-1}$. ${ }^{1} \mathrm{H}$ NMR $\left(500 \mathrm{MHz}, \mathrm{CDCl}_{3}\right): \delta_{\mathrm{H}} 2.43\left(\mathrm{~s}, 3 \mathrm{H},-\mathrm{CH}_{3}\right) ; 6.81(\mathrm{~s}$, $1 \mathrm{H}$, isoxazolinyl- $H) ; 7.26(\mathrm{~s}, 1 \mathrm{H}, \mathrm{Ar}-H) ; 7.36(\mathrm{t}, 1 \mathrm{H}$, $J=7.6 \mathrm{~Hz}, \operatorname{Ar}-H) ; 7.47$ (d, $3 \mathrm{H}, J=6.8 \mathrm{~Hz}, \operatorname{Ar}-H)$; 7.63-7.66 (m, 2H, Ar- $H) ; 7.84(\mathrm{~d}, 1 \mathrm{H}, J=6.1 \mathrm{~Hz}$, $\operatorname{Ar}-H) ; 7.88(\mathrm{~d}, 1 \mathrm{H}, J=8.4 \mathrm{~Hz}, \operatorname{Ar}-H) .{ }^{13} \mathrm{C}$ NMR $\left(125 \mathrm{MHz}, \mathrm{CDCl}_{3}\right): \delta_{\mathrm{C}} 21.5,97.4,123.1,125.9,126.5$, 126.9, 129.0, 129.1, 130.0, 130.9, 131.1, 138.8, 163.0, 170.6. MS (ESI): $m / z=235[\mathrm{M}+]$. Anal. Calcd. for $\mathrm{C}_{16} \mathrm{H}_{13} \mathrm{NO}: \mathrm{C}, 81.68 ; \mathrm{H}, 5.57$; N, 5.95\%. Found: C, $81.55 ; \mathrm{H}, 5.52 ; \mathrm{N}, 6.10 \%$.

$2.2 \mathrm{f} \quad$ 2-(3-Phenyl-isoxazol-5-yl)-benzonitrile (3f): Colourless solid; M.p. 116-118 ${ }^{\circ}$ C; IR (KBr): 3411, 3009, 2222, 1501, 1499, $783 \mathrm{~cm}^{-1}$. ${ }^{1} \mathrm{H}$ NMR $(500$ $\left.\mathrm{MHz}, \mathrm{CDCl}_{3}\right): \delta_{\mathrm{H}} 7.15(\mathrm{~s}, 1 \mathrm{H}$, isoxazolinyl- $H)$; 7.34-7.35 (m, 4H, Ar- $H)$; 7.55-7.56 (m, 2H, Ar- $H)$; 7.82-7.84 (m, 2H, Ar- $H$ ); $8.00(\mathrm{~d}, 1 \mathrm{H}, J=8.4 \mathrm{~Hz}$, Ar- $H) .{ }^{13} \mathrm{C}$ NMR $\left(125 \mathrm{MHz}, \mathrm{CDCl}_{3}\right): \delta_{\mathrm{C}} 101.8,109.1$, $118.0,126.0,127.0,127.8,129.1,129.7,130.1,130.4$, 133.5, 134.3, 163.4, 165.8. MS (ESI): $m / z=246$ $[\mathrm{M}+]$. Anal. Calcd.. for $\mathrm{C}_{16} \mathrm{H}_{10} \mathrm{~N}_{2} \mathrm{O}: \mathrm{C}, 78.04 ; \mathrm{H}, 4.09$; $\mathrm{N}, 11.38 \%$. Found: C, 77.89; H, 4.15; N, 11.50\%.

2.2g 5-(4-Fluoro-Phenyl)-phenyl-isoxazole (3g): Pale yellow solid; M.p. 74-76 ${ }^{\circ}$; IR ( $\left.\mathrm{KBr}\right)$ : 3399, 3014, 1507, 1487, 927, $755 \mathrm{~cm}^{-1}$. ${ }^{1} \mathrm{H}$ NMR $(500 \mathrm{MHz}$, $\left.\mathrm{CDCl}_{3}\right): \delta_{\mathrm{H}} 6.76(\mathrm{~s}, 1 \mathrm{H}$, isoxazolinyl- $H) ; 7.11-7.22$ (m, 2H, Ar- $H$ ); 7.41-7.54 (m, 3H, Ar- $H)$; 7.79-7.92 $(\mathrm{m}, \mathrm{Ar}-H) .{ }^{13} \mathrm{C}$ NMR $\left(125 \mathrm{MHz}, \mathrm{CDCl}_{3}\right): \delta_{\mathrm{C}} 97.3$, $116.2,116.4,125.9,126.8,127.9,128.0,129.0,130.1$, 163.1, 169.5. MS (ESI): $m / z=239$ [M+]. Anal. Calcd. for $\mathrm{C}_{15} \mathrm{H}_{10} \mathrm{FNO}$ : $\mathrm{C}, 75.30 ; \mathrm{H}, 4.21 ; \mathrm{N}, 5.85 \%$. Found: $\mathrm{C}$, $75.01 ; \mathrm{H}, 4.25 ; \mathrm{N}, 5.93 \%$.

$2.2 \mathrm{~h}$ 5-(6-Methoxy-naphthalen-2-yl)-3-phenyl-isoxazole (3h): Brown solid; M.p. $181-183^{\circ} \mathrm{C}$; IR (KBr): 3238, 2961, 1638, 1572, 1406, 1362, 1177, 1099, 847 
$\mathrm{cm}^{-1} .{ }^{1} \mathrm{H}$ NMR $\left(500 \mathrm{MHz}, \mathrm{CDCl}_{3}\right): \delta_{\mathrm{H}} 3.91(\mathrm{~s}, 3 \mathrm{H}$, $\left.-\mathrm{OC}_{3}\right) ; 6.87(\mathrm{~s}, 1 \mathrm{H}$, isoxazolinyl- $H)$; 7.46-7.53 (m, 4H, Ar- $H)$; 7.68-7.71 (m, 4H, Ar- $H)$; 7.81-7.83 (m, $3 \mathrm{H}, \mathrm{Ar}-H) .{ }^{13} \mathrm{C} \mathrm{NMR}\left(125 \mathrm{MHz}, \mathrm{CDCl}_{3}\right): \delta_{\mathrm{C}} 55.5$, 97.2, 119.8, 120.0, 123.6, 125.7, 126.9, 127.6, 128.6, 129.0, 130.0, 130.1, 130.3, 130.4, 135.5, 158.9, 163.1, 170.7. MS (ESI): $m / z=301[\mathrm{M}+]$. Anal. Calcd. for $\mathrm{C}_{20} \mathrm{H}_{15} \mathrm{NO}_{2}$ : C, 79.72; H, 5.02; N, 4.65\%. Found: C, 79.89; H, 4.95; N, $4.50 \%$.

2.2i 5-Methyl-3-p-tolyl-isoxazole (3i): Colourless solid; M.p. 59-61 ${ }^{\circ} \mathrm{C}$; IR (KBr): 3098, 1577, 1152, 1035, 899, $752 \mathrm{~cm}^{-1} \cdot{ }^{1} \mathrm{H}$ NMR $\left(500 \mathrm{MHz}, \mathrm{CDCl}_{3}\right): \delta_{\mathrm{H}}$ $2.39\left(\mathrm{~s}, 3 \mathrm{H}, \mathrm{Ar}-\mathrm{CH}_{3}\right) ; 2.46$ (s, $3 \mathrm{H}$, isoxazolinyl- $\left.\mathrm{CH}_{3}\right)$; $6.26(\mathrm{~s}, 1 \mathrm{H}$, isoxazolinyl- $H) ; 7.24(\mathrm{~d}, 2 \mathrm{H}, J=9.2 \mathrm{~Hz}$, Ar- $H) ; 7.67$ (2H, d, $J=8.0 \mathrm{~Hz}$, Ar-H). ${ }^{13} \mathrm{C}$ NMR $(125$ $\left.\mathrm{MHz}, \mathrm{CDCl}_{3}\right): \delta_{\mathrm{C}} 12.3,21.4,99.6,126.5,126.7,128.8$, 129.5, 139.9, 162.5, 169.6. MS (ESI): $m / z=174$ $[\mathrm{M}+\mathrm{H}]+$. Anal. Calcd. for $\mathrm{C}_{11} \mathrm{H}_{11} \mathrm{NO}: \mathrm{C}, 76.28 ; \mathrm{H}$, $6.40 ; \mathrm{N}, 8.09 \%$. Found: C, 75.99; H, 6.45; N, 8.20\%.

2.2j 2-(3-Phenyl-isoxazol-5-yl)-butan-2-ol (3j): Brown paste; IR (neat): 3479, 3218, 2832, 1573, 1466, 1493, $1254,689 \mathrm{~cm}-1 .{ }^{1} \mathrm{H}$ NMR $\left(500 \mathrm{MHz}, \mathrm{CDCl}_{3}\right): \delta_{\mathrm{H}} 0.93$ $\left(\mathrm{t}, 3 \mathrm{H}, J=6.9 \mathrm{~Hz},-\mathrm{CH}_{2} \mathrm{CH}_{3}\right) ; 1.55\left(\mathrm{~s}, 3 \mathrm{H},-\mathrm{CH}_{3}\right)$; 1.91 (m, 2H, - $\left.\mathrm{CH}_{2} \mathrm{CH}_{3}\right) ; 2.10$ (brs, $\left.-\mathrm{OH}\right) ; 6.46$ (s, $1 \mathrm{H}$, isoxazolinyl- $H$ ); 7.39-7.44 (m, 3H, Ar- $H)$; 7.75-7.78 $(\mathrm{m}, 2 \mathrm{H}, \mathrm{Ar}-H) ;{ }^{13} \mathrm{C}$ NMR $\left(125 \mathrm{MHz}, \mathrm{CDCl}_{3}\right): \delta \mathrm{C} 7.7$, 26.8, 33.2, 89.0, 91.6, 125.9, 126.6, 128.7, 130.9, 166.4, 168.5. MS (ESI): $m / z=217[\mathrm{M}+]$. Anal. Calcd. for $\mathrm{C}_{13} \mathrm{H}_{15} \mathrm{NO}_{2}$ : C, 71.87; H, 6.96; N, 6.45\%. Found: $\mathrm{C}$, $72.01 ; \mathrm{H}, 6.90 ; \mathrm{N}, 6.38 \%$.

2.2k 3-Methyl-5-dimethylphenylsilylisoxazole (3k): Yellow paste; IR (neat): 1590, 1411, 1250, 1100, 1000, $701 \mathrm{~cm}^{-1} .{ }^{1} \mathrm{H}$ NMR $\left(500 \mathrm{MHz}, \mathrm{CDCl}_{3}\right): \delta \mathrm{H} 0.64(\mathrm{~s}, 6 \mathrm{H}$, $\left.-\mathrm{SiPh}\left(\mathrm{CH}_{3}\right)_{2}\right) ; 2.33$ (s, 3H, - $\left.\mathrm{CH}_{3}\right) ; 6.29$ (s, $1 \mathrm{H}$, -isoxazolinyl- $H$ ); 7.32-7.36 (m, 3H, Ar- $H$ ); 7.58-7.62 (m, $2 \mathrm{H}$, Ar- $H) .{ }^{13} \mathrm{C}$ NMR $\left(125 \mathrm{MHz}, \mathrm{CDCl}_{3}\right): \delta_{\mathrm{C}}-0.05,10.7$, 114.6, 127.7, 129.2, 139.9, 157.6, 176.0. MS (ESI): $m / z=217[\mathrm{M}+]$. Anal. Calcd. for $\mathrm{C}_{12} \mathrm{H}_{15} \mathrm{NOSi}$ : C, 66.31; H, 6.96; N, 6.44\%. Found, C, 66.73; H, 7.19; N, $6.31 \%$.

2.21 3-Phenyl-isoxazole (3l): Colourless oil; IR (neat): 3102, 1567, 1147, 1041, 901, $763 \mathrm{~cm}-1$. 1H NMR $\left(500 \mathrm{MHz}, \mathrm{CDCl}_{3}\right): \delta_{\mathrm{H}} 6.64(\mathrm{~d}, 1 \mathrm{H}, J=1.8 \mathrm{~Hz}, 3-$ Isoxazolinyl- $H$ ); 7.42-7.47 (m, $3 \mathrm{H}, \mathrm{Ar}-H) ; 7.80-7.84$ $(\mathrm{m}, 2 \mathrm{H}, \mathrm{Ar}-H) ; 8.44$ (d, $1 \mathrm{H}, J=1.8 \mathrm{~Hz}, 2$-Isoxazolinyl- $H$ ). ${ }^{13} \mathrm{C}$ NMR $\left(125 \mathrm{MHz}, \mathrm{CDCl}_{3}\right): \delta_{\mathrm{C}} 102.2$, 126.7, 128.6, 128.7, 130.0, 159.0, 161.6. MS (ESI): $m / z=145[\mathrm{M}+]$. Anal. Calcd. for $\mathrm{C}_{9} \mathrm{H}_{7} \mathrm{NO}: \mathrm{C}, 74.47$; H, 4.86; N, 9.65\%. Found: C, 74.89; H, 4.81; N, 9.50\%.

$2.2 \mathrm{~m} \quad 3,5$-Diphenyl-isoxazole $\quad(3 \mathrm{~m})$ : Colourless solid; M.p. $140-142^{\circ} \mathrm{C}$; IR (KBr): 3113, 3046, 1613, $1571,1449,1256,1073,821,762 \mathrm{~cm}^{-1}$. M.p. 142$144^{\circ} \mathrm{C} ;{ }^{1} \mathrm{H}$ NMR $\left(500 \mathrm{MHz}, \mathrm{CDCl}_{3}\right): \delta_{\mathrm{H}} 6.83(\mathrm{~s}, 1 \mathrm{H}$, isoxazolinyl- $H) ; 7.44-7.49(\mathrm{~m}, 6 \mathrm{H}, \operatorname{Ar}-H) ; 7.84(\mathrm{~d}$, $2 \mathrm{H}, J=6.9 \mathrm{~Hz}, \operatorname{Ar}-H) ; 7.88(\mathrm{~d}, 2 \mathrm{H}, J=7.6 \mathrm{~Hz}$, Ar- $H$ ). ${ }^{13} \mathrm{C}$ NMR $\left(125 \mathrm{MHz}, \mathrm{CDCl}_{3}\right): \delta_{\mathrm{C}} 97.6,125.9$, 126.9, 127.5, 129.0, 129.1, 129.2, 130.1, 130.5, 163.0, 170.5. MS (ESI): $m / z=221[\mathrm{M}+]$. Anal. Calcd. for $\mathrm{C}_{15} \mathrm{H}_{11} \mathrm{NO}: \mathrm{C}, 81.43 ; \mathrm{H}, 5.01 ; \mathrm{N}, 6.33 \%$. Found: C, $81.65 ; \mathrm{H}, 4.97 ; \mathrm{N}, 6.25 \%$.

2.2n 3-Methyl-5-trimethylsilyl-isoxazole (3n): Yellow liquid; IR (neat): 3302, 2912, 1604, 1419, 1338, $1085,885,757 \mathrm{~cm}^{-1}$. 1H NMR $\left(500 \mathrm{MHz}, \mathrm{CDCl}_{3}\right): \delta_{\mathrm{H}}$ 0.29 (s, 9H, $\left.-\mathrm{Si}\left(\mathrm{CH}_{3}\right)_{3}\right) ; 2.29$ (s, 3H, $\left.-\mathrm{CH}_{3}\right) ; 6.24$ (s, $1 \mathrm{H}$, isoxazolinyl- $H) .{ }^{13} \mathrm{C} \mathrm{NMR}\left(125 \mathrm{MHz}, \mathrm{CDCl}_{3}\right): \delta_{\mathrm{C}}$ -1.8, 10.8, 113.5, 157.7, 177.8. MS (ESI): $m / z=155$ $[\mathrm{M}+]$. Anal. Calcd. for $\mathrm{C}_{7} \mathrm{H}_{13} \mathrm{NOSi}$ : C, 54.15; H, 8.44; N, 9.02\%. Found: C, 53.95; H, 8.47; N, 9.15\%.

2.2o 5-(3-Methoxy-phenyl)-isoxazole (3o): Yellow oil; IR (KBr): 3302, 2219, 1604, 1419, 1338, 1085, 885, $757 \mathrm{~cm}^{-1} .{ }^{1} \mathrm{H}$ NMR $\left(500 \mathrm{MHz}, \mathrm{CDCl}_{3}\right): \delta_{\mathrm{H}} 3.83(\mathrm{~s}$, $\left.3 \mathrm{H},-\mathrm{OCH}_{3}\right) ; 6.48(\mathrm{~d}, 1 \mathrm{H}, J=2.2 \mathrm{~Hz}$, isoxazolinyl$H)$; 6.94-6.96 (m, $1 \mathrm{H}, \operatorname{Ar}-H)$; 7.31 (s, $1 \mathrm{H}, \operatorname{Ar}-H) ; 7.34$ $(\mathrm{d}, 2 \mathrm{H}, J=5.3 \mathrm{~Hz}, \operatorname{Ar}-H) ; 8.26(\mathrm{~d}, 1 \mathrm{H}, J=1.5$ $\mathrm{Hz}$, isoxazolinyl- $H) .{ }^{13} \mathrm{C} \mathrm{NMR}\left(125 \mathrm{MHz}, \mathrm{CDCl}_{3}\right): \delta_{\mathrm{C}}$ 55.4, 99.0, 111.0, 116.2, 118.4, 128.4, 130.2, 150.9, 160.0, 169.2. MS (ESI): $m / z=175$ [M+]. Anal. Calcd. for $\mathrm{C}_{10} \mathrm{H}_{9} \mathrm{NO}_{2}$ : C, 68.56; H, 5.18; N, 8.00\%. Found: C, $68.75 ; \mathrm{H}, 5.10 ; \mathrm{N}, 7.95 \%$.

2.2p 3-p-Tolyl-isoxazole (3p): Colourless solid; M.p. 56-58 ${ }^{\circ}$; IR (KBr): 3301, 1609, 1420, 889, 729 $\mathrm{cm}^{-1} .{ }^{1} \mathrm{H}$ NMR $\left(500 \mathrm{MHz}, \mathrm{CDCl}_{3}\right): \delta_{\mathrm{H}} 2.39(\mathrm{~s}, 3 \mathrm{H}$, $\left.-\mathrm{CH}_{3}\right) ; 6.63(\mathrm{~d}, 1 \mathrm{H}, J=1.8 \mathrm{~Hz}, 3$ rd-Isoxazolinyl- $H)$; 7.27 (d, 2H, $J=7.8 \mathrm{~Hz}, \operatorname{Ar}-H) ; 7.70$ (d, 2H, $J=8.1$ $\mathrm{Hz}, \operatorname{Ar}-H) ; 8.42(\mathrm{~d}, 1 \mathrm{H}, J=1.8 \mathrm{~Hz}, 2$ nd-Isoxazolinyl$H) .{ }^{13} \mathrm{C} \mathrm{NMR}\left(125 \mathrm{MHz}, \mathrm{CDCl}_{3}\right): \delta_{\mathrm{C}} 21.5,102.5$, 126.0, 126.6, 129.7, 140.2, 158.9, 161.6. MS (ESI): $m / z=159[\mathrm{M}+]$. Anal. Calcd. for $\mathrm{C}_{10} \mathrm{H}_{9} \mathrm{NO}: \mathrm{C}, 75.45$; H, 5.70; N, 8.80\%. Found: C, 75.75; H, 5.62; N, 8.69\%.

2.2q 5-Propyl-isoxazole (3q): Yellow oil; IR (neat): 2979, 1730, 1469, 1354, 1328, 1118, $738 \mathrm{~cm}^{-1} .{ }^{1} \mathrm{H}$ NMR $\left(500 \mathrm{MHz}, \mathrm{CDCl}_{3}\right): \delta_{\mathrm{H}} 0.97(\mathrm{t}, 3 \mathrm{H}, J=6.9 \mathrm{~Hz}$, 
$\left.-\mathrm{CH}_{3}\right) ; 1.54-1.58\left(\mathrm{~m}, 2 \mathrm{H},-\mathrm{CH}_{2} \mathrm{CH}_{3}\right) ; 2.30(\mathrm{t}, 2 \mathrm{H}, \mathrm{J}=$ $7.6 \mathrm{~Hz},-\mathrm{CH}_{2} \mathrm{CH}_{2} \mathrm{CH}_{3}$ ); 6.73 (s, $1 \mathrm{H}$, isoxazolinyl- $H$ ); $7.34(\mathrm{~d}, 1 \mathrm{H}, J=1.5 \mathrm{~Hz}$, isoxazolinyl- $H) .{ }^{13} \mathrm{C}$ NMR $\left(125 \mathrm{MHz}, \mathrm{CDCl}_{3}\right): \delta_{\mathrm{C}} 13.5,21.4,21.6,96.8,130.9$, 135.0. MS (ESI): $m / z=111$ [M+]. Anal. Calcd. for $\mathrm{C}_{6} \mathrm{H}_{9} \mathrm{NO}: \mathrm{C}, 64.84 ; \mathrm{H}, 8.16 ; \mathrm{N}, 12.60 \%$. Found: C, $65.00 ; \mathrm{H}, 8.12 ; \mathrm{N}, 12.55 \%$.

2.2r 5-Pentyl-isoxazole (3r): Yellow oil; IR (neat): 2980, 1727, 1475, 1360, 1720, $740 \mathrm{~cm}^{-1} .{ }^{1} \mathrm{H}$ NMR (500 $\left.\mathrm{MHz}, \mathrm{CDCl}_{3}\right): \delta_{\mathrm{H}} 0.87\left(\mathrm{t}, 3 \mathrm{H}, J=6.9 \mathrm{~Hz},-\mathrm{CH}_{3}\right)$; 1.45-1.59 (m, 4H, $\left.-\left(\mathrm{CH}_{2}\right)_{2} \mathrm{CH}_{3}\right) ; 1.68(\mathrm{q}, 2 \mathrm{H}, J=$ $\left.6.8 \mathrm{~Hz},-\mathrm{CH}_{2}\left(\mathrm{CH}_{2}\right)_{2} \mathrm{CH}_{3}\right) ; 2.74(\mathrm{t}, 2 \mathrm{H}, J=7.6 \mathrm{~Hz}$, $\left.\mathrm{CH}_{2}\left(\mathrm{CH}_{2}\right)_{3} \mathrm{CH}_{3}\right) ; 5.94$ (s, $1 \mathrm{H}$, isoxazolinyl- $\left.H\right) ; 8.11$ (d, $1 \mathrm{H}, J=1.5 \mathrm{~Hz}$, isoxazolinyl- $H) .{ }^{13} \mathrm{C}$ NMR $(125 \mathrm{MHz}$, $\left.\mathrm{CDCl}_{3}\right): \delta_{\mathrm{C}} 13.9,22.3,26.5,27.2,31.2,99.9,150.2$, 173.1. MS (ESI): $m / z=139$ [M+]. Anal. Calcd. for $\mathrm{C}_{8} \mathrm{H}_{13} \mathrm{NO}: \mathrm{C}, 69.03 ; \mathrm{H}, 9.41 ; \mathrm{N}, 10.06 \%$. Found: C, $68.92 ; \mathrm{H}, 9.45 ; \mathrm{N}, 10.10 \%$.

\subsection{General Procedure for the synthesis of pyrazoles $(5 a-5 j)$}

To a solution of hydrazone $4(1.0 \mathrm{mmol})$ in dry dichloromethane was added $\mathrm{AuCl}_{3}(0.01 \mathrm{mmol})$ under $\mathrm{N}_{2}$ atmosphere and stirred at the specified time and temperature (table 2). After completion of the reaction as indicated by TLC the reaction mixture was concentrated under reduced pressure and purified by column chromatography over silica gel (100-200 mesh) to afford the pure product of pyrazole 5 .

2.3a 1,5-Diphenyl-1H-pyrazole (5a): ${ }^{1} \mathrm{H}$ NMR (500 $\left.\mathrm{MHz}, \mathrm{CDCl}_{3}\right): \delta_{\mathrm{H}} 6.55(\mathrm{~d}, 1 \mathrm{H}, J=1.6 \mathrm{~Hz}) ; 7.28-7.30$ $(\mathrm{m}, 2 \mathrm{H}) ; 7.32-7.37(\mathrm{~m}, 8 \mathrm{H}) ; 7.77(\mathrm{~s}, 1 \mathrm{H}, J=1.6 \mathrm{~Hz})$. ${ }^{13} \mathrm{C}$ NMR (125 MHz, CDCl3): $\delta_{\mathrm{C}} 107.7,125.1,127.3$,

Table 2. Cyclization of hydrazones 4 to 5 .

\begin{tabular}{lcccccc}
\hline Entry & $\mathrm{R}$ & $\mathrm{R}^{1}$ & $\mathrm{R}^{2}$ & $\begin{array}{c}\text { Product } \\
\mathbf{5}^{\mathrm{a}}\end{array}$ & $\begin{array}{c}\text { Time } \\
(\mathrm{h})\end{array}$ & $\begin{array}{c}\text { Yield } \\
(\%)^{\mathrm{b}}\end{array}$ \\
\hline 1 & $\mathrm{H}$ & $\mathrm{Ph}$ & $\mathrm{Ph}$ & $\mathbf{5 a}$ & 1.5 & 75 \\
2 & $\mathrm{H}$ & $p$-tolyl & $\mathrm{Ph}$ & $\mathbf{5 b}$ & 1.5 & 80 \\
3 & $\mathrm{H}$ & $p$-anisyl & $\mathrm{Ph}$ & $\mathbf{5 c}$ & 1.5 & 79 \\
4 & $\mathrm{H}$ & $\mathrm{Pentyl}$ & $\mathrm{Ph}$ & $\mathbf{5 d}$ & 2.0 & 67 \\
5 & $\mathrm{Me}$ & $\mathrm{Ph}$ & $\mathrm{Ph}$ & $\mathbf{5 e}$ & 1.0 & 85 \\
6 & $\mathrm{Ph}$ & $\mathrm{Ph}$ & $\mathrm{Ph}$ & $\mathbf{5 f}$ & 1.0 & 88 \\
7 & $\mathrm{Me}$ & $\mathrm{Ph}$ & $p$ - $\mathrm{CF}_{3} \mathrm{Ph}$ & $\mathbf{5 g}$ & 4.5 & 55 \\
8 & $\mathrm{H}$ & $p$-tolyl & $p-\mathrm{CF}_{3} \mathrm{Ph}$ & $\mathbf{5 h}$ & 4.0 & 62 \\
9 & $\mathrm{Ph}$ & $\mathrm{Ph}$ & $p$-CF $3 \mathrm{Ph}$ & $\mathbf{5 i}$ & 4.5 & 59 \\
10 & $\mathrm{H}$ & $p$-anisyl & $p$-CF $\mathrm{CF}_{3} \mathrm{Ph}$ & $\mathbf{5 j}$ & 4.0 & 64 \\
\hline
\end{tabular}

${ }^{\mathrm{a}}$ All products were characterized by IR, NMR and mass.

${ }^{\mathrm{b}}$ Isolated yield after column chromatography.
128.1, 128.3, 128.7, 129.0, 130.5, 140.1, 142.9. MS (ESI): $m / z=220[\mathrm{M}+]$. Anal. Calcd. for $\mathrm{C}_{15} \mathrm{H}_{12} \mathrm{~N}_{2}$ : C, 81.79; H, 5.49; N, 12.72\%. Found: C, 82.02; H, 5.45; $\mathrm{N}, 12.53 \%$.

2.3b 1-Phenyl-5-(p-tolyl)-1H-pyrazole (5b): IR (neat) 3452, 2922, 1611, 1451, 1309, 1159, 1072, $761 \mathrm{~cm}^{-1}$. 1H NMR $\left(500 \mathrm{MHz}, \mathrm{CDCl}_{3}\right): \delta_{\mathrm{H}} 2.38(\mathrm{~s}$, $3 \mathrm{H}) ; 6.50(\mathrm{~d}, 1 \mathrm{H}, J=1.6 \mathrm{~Hz}) ; 7.12-7.18(\mathrm{~m}, 4 \mathrm{H})$; 7.31-7.38 (m, 5H); $7.75(\mathrm{~d}, 1 \mathrm{H}, J=1.5 \mathrm{~Hz}), 7.35(\mathrm{~m}$, $5 \mathrm{H}), 7.15(\mathrm{~m}, 4 \mathrm{H}), 6.51(\mathrm{~d}, J=1.5 \mathrm{~Hz}, 1 \mathrm{H}), 2.37(\mathrm{~s}$, $3 \mathrm{H})$. MS (ESI): $m / z=235\left[\mathrm{M}+\mathrm{H}^{+}\right]$. Anal. Calcd. for $\mathrm{C}_{16} \mathrm{H}_{14} \mathrm{~N}_{2}$ : C, 82.02; H, 6.02; N, 11.96\%. Found: C, $81.82 ; \mathrm{H}, 6.07 ; \mathrm{N}, 12.11 \%$.

2.3c 5-(4-Methoxyphenyl)-1-phenyl-1H-pyrazole (5c): IR (neat): 3133, 2930, 1600, 1499, 1441, 1385, 1245, 1175, 960, $759 \mathrm{~cm}^{-1} .{ }^{1} \mathrm{H}$ NMR (500 $\left.\mathrm{MHz}, \mathrm{CDCl}_{3}\right)$ : $\delta \mathrm{H} 3.75(\mathrm{~s}, 3 \mathrm{H}) ; 6.41(\mathrm{~d}, 1 \mathrm{H}, J=1.2 \mathrm{~Hz}) ; 6.78(\mathrm{~d}$, $1 \mathrm{H}, J=8.5 \mathrm{~Hz}) ; 7.15(\mathrm{~d}, J=8.6 \mathrm{~Hz}, 2 \mathrm{H}) ; 7.27-$ $7.32(\mathrm{~m}, 5 \mathrm{H}) ; 7.67(\mathrm{~d}, 1 \mathrm{H}, J=1.2 \mathrm{~Hz}) \cdot{ }^{13} \mathrm{C} \mathrm{NMR}$ (125 MHz, CDCl3): $\delta_{\mathrm{C}} 55.1,107.2,114.0,122.9,125.3$, 127.2, 129.0, 130.1, 140.1, 140.2, 142.9, 159.5. MS (ESI): $m / z=250[\mathrm{M}+]$. Anal. Calcd. for $\mathrm{C}_{16} \mathrm{H}_{14} \mathrm{~N}_{2} \mathrm{O}$ : C, 76.78; H, 5.64; N, 11.19\%. Found: C, 77.00; H, 5.60; $\mathrm{N}, 11.11 \%$.

2.3d 5-Pentyl-1-phenyl-1H-pyrazole (5d): IR (neat) 2954, 2929, 286, 1598, 1537, 1500, 1454, 1394, 1012, 923, $761 \mathrm{~cm}^{-1} .{ }^{1} \mathrm{H}$ NMR $\left(500 \mathrm{MHz}, \mathrm{CDCl}_{3}\right): \delta_{\mathrm{H}} 0.82$ $(\mathrm{t}, 3 \mathrm{H}, J=7.6 \mathrm{~Hz}) ; 1.22-1.27(\mathrm{~m}, 4 \mathrm{H}) ; 1.55(\mathrm{p}, 2 \mathrm{H}$, $J=7.6 \mathrm{~Hz}) ; 2.61(\mathrm{t}, 2 \mathrm{H}, J=7.6 \mathrm{~Hz}) ; 6.20(\mathrm{~s}, 1 \mathrm{H})$; 7.37-7.41 (m, 5H); $7.65(\mathrm{~d}, 1 \mathrm{H}, J=1.6 \mathrm{~Hz}) .{ }^{13} \mathrm{C} \mathrm{NMR}$ $\left(125 \mathrm{MHz}, \mathrm{CDCl}_{3}\right): \delta_{\mathrm{C}} 13.2,22.2,26.1,28.5,31.3$, 105.2, 125.3, 127.9, 129.0, 139.8, 140.0, 143.7. MS (ESI): $m / z=215[\mathrm{M}+]$. Anal. Calcd. for $\mathrm{C}_{14} \mathrm{H}_{18} \mathrm{~N}_{2}: \mathrm{C}$, 78.46; H, 8.47; N, $13.07 \%$. Found: C, 78.66; H, 8.42; $\mathrm{N}, 12.92 \%$.

2.3e 3-Methyl-1,5-diphenyl-1H-pyrazole (5e): Yellow paste, IR $\left(\mathrm{CH}_{2} \mathrm{Cl}_{2}\right)$ : 3060, 2958, 2865, 1596, 1500, $1451,1369 \mathrm{~cm}^{-1} .{ }^{1} \mathrm{H}$ NMR $\left(500 \mathrm{MHz}, \mathrm{CDCl}_{3}\right): \delta_{\mathrm{H}} 2.40$ (s, 3H); $6.35(\mathrm{~s}, 1 \mathrm{H})$; 7.22-7.25 (m, 2H); 7.27-7.35 (m, $8 \mathrm{H}) .{ }^{13} \mathrm{C}$ NMR $(125 \mathrm{MHz}, \mathrm{CDCl} 3): \delta_{\mathrm{C}} 13.7,107.5$, 125.0, 127.8, 128.8, 128.9, 129.7, 129.9, 130.9, 140.5, 143.9. MS (ESI): $m / z=234$ [M+]. Anal. Calcd. for $\mathrm{C}_{14} \mathrm{H}_{18} \mathrm{~N}_{2}$ : C, 82.02; H, 6.02; N, 11.96\%. Found: C, 82.22; H, 6.07; N, $12.11 \%$.

$2.3 \mathrm{f}$ 1,3,5-Triphenyl-1H-pyrazole (5f): IR (neat) $3064,1612,1550,1523,1483,1458,1323,1166$, 
1056, 968, $763 \mathrm{~cm}^{-1} .{ }^{1} \mathrm{H}$ NMR (500 MHz, CDCl3): $\delta_{\mathrm{H}} 6.85(\mathrm{~s}, 1 \mathrm{H}) ; 7.33-7.37(\mathrm{~m}, 8 \mathrm{H}) ; 7.41-7.45(\mathrm{~m}, 3 \mathrm{H})$; $7.50(\mathrm{t}, 2 \mathrm{H}, J=7.6 \mathrm{~Hz}) ; 8.0(\mathrm{~d}, 2 \mathrm{H}, J=7.6 \mathrm{~Hz})$. ${ }^{13} \mathrm{C} \mathrm{NMR}\left(125 \mathrm{MHz}, \mathrm{CDCl}_{3}\right): \delta_{\mathrm{C}} 105.2,125.3,126.0$, $127.3,128.0,128.2,128.6,128.8,128.9,129.0,128.2$, 128.5, 128.6, 128.9, 129.0, 130.7, 133.1, 140.2, 144.5, 152.1. MS (ESI): $m / z=296[\mathrm{M}+]$. Anal. Calcd. for $\mathrm{C}_{21} \mathrm{H}_{16} \mathrm{~N}_{2}$ : C, 85.11; H, 5.44; N, 9.45\%. Found: C, $84.90 ; \mathrm{H}, 5.50 ; \mathrm{N}, 9.60 \%$.

2.3g 3-Methyl-5-phenyl-1-(4-(trifluoromethyl)phenyl)1H-pyrazole (5g): IR (neat) 3060, 2923, 2851, 1615, 1520, 1499, 1361, 1162, $760 \mathrm{~cm}^{-1} .{ }^{1} \mathrm{H}$ NMR (500 $\left.\mathrm{MHz}, \mathrm{CDCl}_{3}\right): \delta \mathrm{H} 2.30(\mathrm{~s}, 3 \mathrm{H}) ; 6.25(\mathrm{~s}, 1 \mathrm{H}) ; 7.11-$ $7.15(\mathrm{~m}, 2 \mathrm{H}) ; 7.19-7.23(\mathrm{~m}, 3 \mathrm{H}) ; 7.29(\mathrm{~d}, 2 \mathrm{H}, J=$ $8.1 \mathrm{~Hz}) ; 7.45(\mathrm{~d}, 2 \mathrm{H}, J=8.4 \mathrm{~Hz}) .{ }^{13} \mathrm{C}$ NMR $(125$ $\left.\mathrm{MHz}, \mathrm{CDCl}_{3}\right): \delta_{\mathrm{C}} 13.4,109.0,124.5(\mathrm{~d}, J=269 \mathrm{~Hz})$; $124.6,123.0,128.5,128.7,128.8,129.0$ (q, $J=9.1$ Hz); 130.5, 143.0, 144.0, 150.3. MS (ESI): $m / z=302$ $[\mathrm{M}+]$. Anal. Calcd. for $\mathrm{C}_{17} \mathrm{H}_{13} \mathrm{~F}_{3} \mathrm{~N}_{2}$ : C, 67.54; H, 4.33; N, 9.27\%. Found: C, 67.00; H, 4.38; N, 9.35\%.

2.3h 5-(p-Tolyl)-1-(4-(trifluoromethyl)phenyl)-1H-pyrazole (5h): IR (neat) 2921, 1616, 1521, 1419, 1380, 1059, 920, 817, $777 \mathrm{~cm}^{-1}$. ${ }^{1} \mathrm{H}$ NMR $(500 \mathrm{MHz}$, $\left.\mathrm{CDCl}_{3}\right): \delta_{\mathrm{H}} 2.36(\mathrm{~s}, 3 \mathrm{H}) ; 6.47(\mathrm{~d}, 1 \mathrm{H}, J=1.6 \mathrm{~Hz}) ; 7.12$ $(\mathrm{d}, 2 \mathrm{H}, J=8.4 \mathrm{~Hz}) ; 7.15(\mathrm{~d}, 2 \mathrm{H}, J=8.4 \mathrm{~Hz}) ; 7.41(\mathrm{~d}$, $2 \mathrm{H}, J=8.4 \mathrm{~Hz}) ; 7.55(\mathrm{~d}, 2 \mathrm{H}, J=8.4 \mathrm{~Hz}) ; 7.70(\mathrm{~d}$, $1 \mathrm{H}, J=1.6 \mathrm{~Hz}, 1 \mathrm{H}), 7.57(\mathrm{~d}, J=8.5 \mathrm{~Hz}, 2 \mathrm{H}), 7.42$ $(\mathrm{d}, J=8.4 \mathrm{~Hz}, 2 \mathrm{H}), 7.14(\mathrm{~d}, J=8.3 \mathrm{~Hz}, 2 \mathrm{H}), 7.11$ $(\mathrm{d}, J=8.3 \mathrm{~Hz}, 2 \mathrm{H}), 6.48(\mathrm{~d}, J=1.4 \mathrm{~Hz}, 1 \mathrm{H}), 2.35$ (s, 3H). ${ }^{13} \mathrm{C}$ NMR $\left(125 \mathrm{MHz}, \mathrm{CDCl}_{3}\right): \delta_{\mathrm{C}} 21.3,108.5$, $124.0(\mathrm{~d}, J=276 \mathrm{~Hz}), 124.7,126.0,127.4,128.6$, $129.0(\mathrm{~d}, J=35 \mathrm{~Hz}), 129.3,138.6,141.0,143.0$, 143.5. MS (ESI): $m / z=288[\mathrm{M}+]$. Anal. Calcd. for $\mathrm{C}_{16} \mathrm{H}_{11} \mathrm{~F}_{3} \mathrm{~N}_{2}$ : C, 66.66; H, 3.85; N, 9.72\%. Found: C, $66.83 ; \mathrm{H}, 3.80 ; \mathrm{N}, 9.60 \%$.

2.3i 3,5-Diphenyl-1-(4-(trifluoromethyl)phenyl)-1H-pyrazole (5i): IR (neat) 3065, 1614, 1550, 1523, 1455, 1362, 1105, 1056, 916, 810, $760 \mathrm{~cm}^{-1}$. ${ }^{1} \mathrm{H}$ NMR (500 $\left.\mathrm{MHz}, \mathrm{CDCl}_{3}\right): \delta_{\mathrm{H}} 6.75(\mathrm{~s}, 1 \mathrm{H}) ; 7.17-7.21(\mathrm{~m}, 4 \mathrm{H}) ; 7.35$ $(\mathrm{t}, 2 \mathrm{H}, J=7.6 \mathrm{~Hz}) ; 7.39(\mathrm{~d}, 2 \mathrm{H}, J=8.4 \mathrm{~Hz}) ; 7.50(\mathrm{~d}$, $2 \mathrm{H}, J=8.4 \mathrm{~Hz}) ; 7.82(\mathrm{~d}, 2 \mathrm{H}, J=7.6 \mathrm{~Hz}) .{ }^{13} \mathrm{C} \mathrm{NMR}$ $\left(125 \mathrm{MHz}, \mathrm{CDCl}_{3}\right): \delta_{\mathrm{C}} 106.2,124.0(\mathrm{~d}, J=276 \mathrm{~Hz})$, $124.8,126.0,126.1,127.9,128.2,128.6,128.8,128.9$, $129.0(\mathrm{~d}, J=35 \mathrm{~Hz}), 130.2,132.7,143.0,144.6$, 152.6. MS (ESI): $m / z=364[\mathrm{M}+]$. Anal. Calcd. for $\mathrm{C}_{22} \mathrm{H}_{15} \mathrm{~F}_{3} \mathrm{~N}_{2}$ : C, 72.52; H, 4.15; $\mathrm{N}, 7.69 \%$. Found: $\mathrm{C}$, $72.01 ; \mathrm{H}, 4.23 ; \mathrm{N}, 7.80 \%$. 2.3j 5-(4-Methoxyphenyl)-1-(4-(trifluoromethyl)phenyl)-1H-pyrazole (5j): IR (neat) 2846, 1614, 1521, 1498, 1251, 1161, 1029, 960, 837, $792 \mathrm{~cm}^{-1} .{ }^{1} \mathrm{H}$ NMR $\left(500 \mathrm{MHz}, \mathrm{CDCl}_{3}\right): \delta \mathrm{H} 3.79(\mathrm{~s}, 3 \mathrm{H}) ; 6.45(\mathrm{~d}, 1 \mathrm{H}, J=$ $1.2 \mathrm{~Hz}) ; 6.85(\mathrm{~d}, 2 \mathrm{H}, J=8.6 \mathrm{~Hz}) ; 7.15(\mathrm{~d}, 2 \mathrm{H}, J=$ $8.6 \mathrm{~Hz}) ; 7.45(\mathrm{~d}, 2 \mathrm{H}, J=8.6 \mathrm{~Hz}) ; 7.57(\mathrm{~d}, 2 \mathrm{H}, J=$ $8.6 \mathrm{~Hz}) ; 7.71(\mathrm{~d}, 1 \mathrm{H}, J=1.2 \mathrm{~Hz}) .{ }^{13} \mathrm{C}$ NMR $(125$ $\left.\mathrm{MHz}, \mathrm{CDCl}_{3}\right): \delta_{\mathrm{C}} 55.2,108.3,114.1,122.5,124.0(\mathrm{~d}$, $J=276 \mathrm{~Hz}), 124.8,125.9,129.0(\mathrm{~d}, J=35 \mathrm{~Hz})$, 130.0, 141.1, 143.0, 143.1, 160.0. MS (ESI): $m / z=$ $318[\mathrm{M}+]$. Anal. Calcd. for $\mathrm{C}_{17} \mathrm{H}_{13} \mathrm{~F}_{3} \mathrm{~N}_{2} \mathrm{O}: \mathrm{C}, 64.15 ; \mathrm{H}$, 4.12 ; N, 8.80\%. Found: C, 63.96; H, 4.18; N, 8.91\%.

\subsection{Experimental procedure for the evaluation of cytotoxicity}

The MTT [3-(4,5-dimethylthiazo-2-yl)-2,5-diphenyltetrazolium bromide] cell proliferation assay was used to evaluate the cytotoxic activity of the synthesized compounds against COLO320 adenocarcinoma colorectal cancer cell lines. ${ }^{6}$ COLO320 cancer cell line was maintained in complete tissue culture medium RPMI with $10 \%$ Fetal Bovine Serum and $2 \mathrm{mM} \mathrm{L-}$ Glutamine, along with antibiotics (about $100 \mathrm{IU} / \mathrm{mL}$ of penicillin, $100 \mu \mathrm{g} / \mathrm{mL}$ of streptomycin) with the $\mathrm{pH}$ adjusted to 7.2 . Cells $\left(5 \times 10^{5}\right)$ were seeded in 96 well plates containing medium with different concentrations such as $500 \mu \mathrm{g} / \mathrm{mL}, 250 \mu \mathrm{g} / \mathrm{mL}$ and $100 \mu \mathrm{g} / \mathrm{mL}$. The cells were cultivated at $37^{\circ} \mathrm{C}$ with $5 \% \mathrm{CO}_{2}$ and $95 \%$ air in $100 \%$ relative humidity. After various durations of cultivation, the solution in the medium was removed. An aliquot of $100 \mu \mathrm{L}$ of medium containing $1 \mathrm{mg} / \mathrm{mL}$ of MTT was loaded to the plate. Incubation at $37^{\circ} \mathrm{C}$ for $4 \mathrm{~h}$ allowed reduction of MTT by mitochondrial dehydrogenase to an insoluble formazan product. Well contents were removed and the formazan product was solubilized by the addition of $100 \mu \mathrm{L}$ of DMSO, which led to the formation of purple colour. The amount of formazan product is directly proportional to the number of living cells. Absorbance of the converted dye in each well was read on ELISA reader at $570 \mathrm{~nm}$. From the absorbance, $\%$ of inhibition was calculated by using the formula, \% of inhibition $=($ Ac-At $) / A c X 100$, where Ac is the mean absorbance of control and At is that of test. From the results, non-linear regression graph was plotted between \% cell growth inhibition and $\log _{10}$ concentration $(\mu \mathrm{M})$. The half maximal inhibitory concentration $\left(\mathrm{IC}_{50}\right.$ value) was determined and averaged from three replicate experiments. Cytotoxicity was statistically analyzed by Duncan multiple range test at $\mathrm{P}$ $=0.05$ with the help of SPSS 11.5 version software package. 


\section{Results and Discussion}

\subsection{Chemistry}

As part of our research endeavour of gold catalysis for carbo- and heterocycle construction, we have previously reported the $\mathrm{AuCl}_{3}$ catalyzed cyclization of $\alpha, \beta$-acetylenic oximes leading to substituted isoxazoles (scheme 1). ${ }^{2 \mathrm{e}}$ The chemical synthesis of requisite oximes $\mathbf{2}$ commenced from the condensation of acetylenic aldehydes/ketones $\mathbf{1}$ with hydroxylamine. ${ }^{7}$ The cyclization of acetylenic oximes $\mathbf{2}$ was effected by the catalytic use of $\mathrm{AuCl}_{3}(1 \mathrm{~mol} \%)$ in dichloromethane at room temperature which results in the formation of isoxazoles 3. Under this reaction condition, all substrates underwent the reaction completely and resulted in good yields of the product as summarized in table 1 . However, the rate of the reaction seems to be dependent on the substituent on the substrates. Oximes having electron releasing group on the alkyne residue (entries $1-5,9,13$ and 15-18) more readily underwent the cyclization than those possessing electron withdrawing groups (entries 6 and 7). The reaction condition was also amenable to substituent possessing hydroxyl and polyaromatic functionalities albeit in moderate yields (entries 8 and 10). The substrates (2k and $\mathbf{2 n}$ ) possessing silyl group underwent the cyclization only after reflux for $30 \mathrm{~min}$. This can be attributed to the presence of electron withdrawing silyl group which renders the triple bond electron deficient, thus making the nucleophile $(=\mathrm{N}-\mathrm{OH})$, difficult to attack the triple bond. The cycloisomerization of silyl oximes $(\mathbf{2 k}$ and $2 \mathrm{n}$ ) by this methodology seems to be beneficial as the silyl group was left intact, whereas in the related $\mathrm{K}_{2} \mathrm{CO}_{3}$ method, desilylated product was obtained. ${ }^{8}$ One of the noteworthy advantages of this methodology is the cycloisomerization of oximes possessing terminal alkyne (2l) leading to 3-substituted isoxazole (3l), whilst similar type of cyclization uses only internal alkynes leading to the formation of 3,5-disubstituted isoxazoles. $^{7}$

The isoxazole products were characterized by IR, ${ }^{1} \mathrm{H}$ NMR, ${ }^{13} \mathrm{C}$ NMR and mass. All compounds exhibited a sharp singlet in their ${ }^{1} \mathrm{H}$ NMR spectrum at $\delta_{\mathrm{H}}=6.2$ $6.8 \mathrm{ppm}$, characteristic of isoxazolinyl proton. In ${ }^{13} \mathrm{C}$ NMR, the characteristic peak of C5 carbon of the isoxazole ring was exhibited at $\delta_{\mathrm{C}}=170.0-170.9 \mathrm{ppm}$. As a final proof, single crystal of compounds $\mathbf{3} \mathbf{c}$ and $\mathbf{3 e}$ was obtained by recrystallization and the structure was unambiguously confirmed by X-ray diffraction studies (figures 2 and 3). ${ }^{9}$

With an efficient protocol for the synthesis of isoxazoles in hand, we next set out to investigate the scope and limitations of our gold catalytic system towards

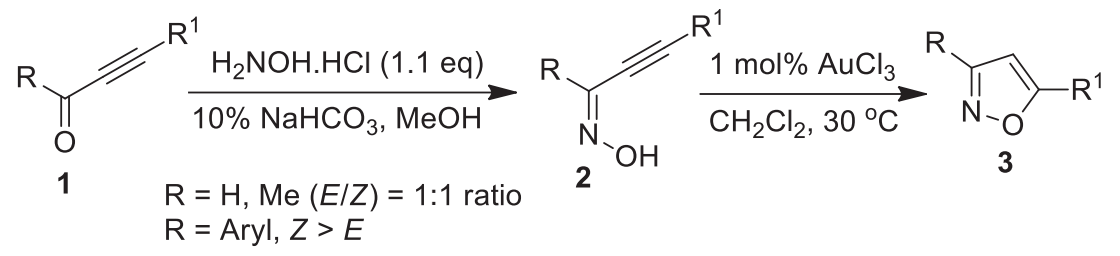

Scheme 1. Synthesis of isoxazoles.

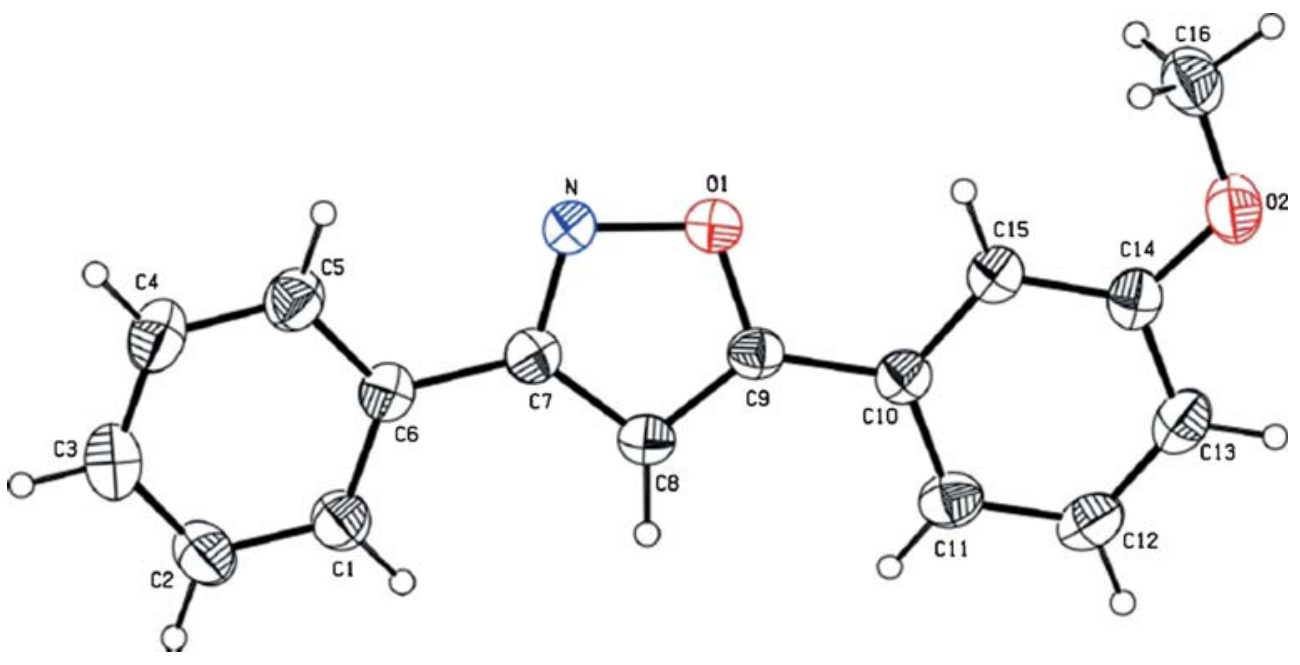

Figure 2. ORTEP diagram of compound $\mathbf{3 c}$. 


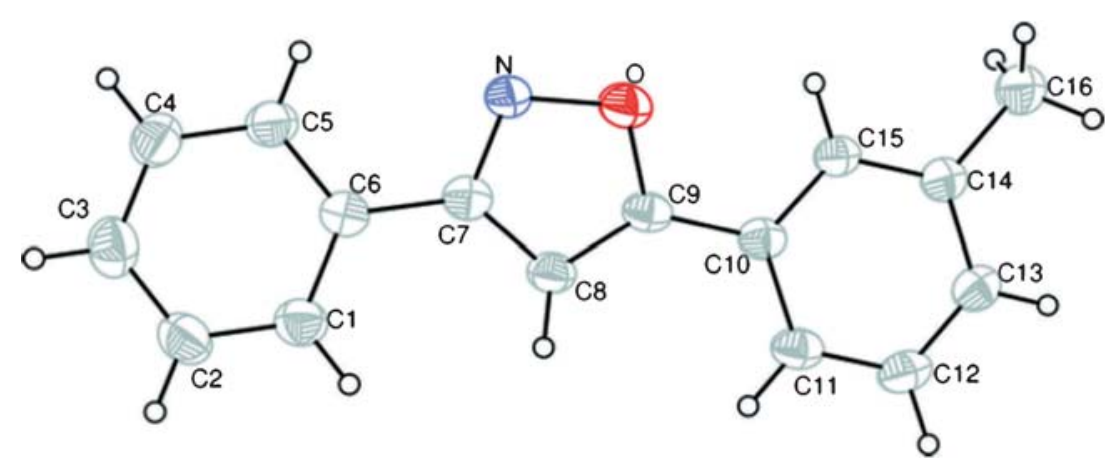

Figure 3. ORTEP diagram of compound $\mathbf{3 e}$.

$\alpha, \beta$-acetylenic hydrazones for the synthesis of pyrazoles (scheme 2). The requisite $\alpha, \beta$-acetylenic hydrazones $\mathbf{4}$ has been prepared in satisfactory yield through the condensation of acetylenic aldehydes/ketones $\mathbf{1}$ with arylhydrazines. ${ }^{10}$ By subjecting the precursors $\mathbf{4}$ under our previously demonstrated conditions ( $1 \mathrm{~mol} \%$ $\mathrm{AuCl}_{3}, \mathrm{CH}_{2} \mathrm{Cl}_{2}$ ), we found that the reaction proceeded smoothly and afforded the pyrazole products, albeit not with the exceptional efficiency of the isoxazoles as evidenced by the reduced yield (table 2). The effect of the substituent on the hydrazone nitrogen was explored using phenyl and $p-\mathrm{CF}_{3} \mathrm{Ph}$ groups. We found that hydrazones having a highly electron withdrawing substituent such as $p-\mathrm{CF}_{3} \mathrm{Ph}(\mathbf{5 g}-\mathbf{5 j})$ led to reasonable conversion with only an increase of the reaction time as compared to that of phenyl groups (5a-5f). The presence of other substituent viz. $\mathrm{R}$ and $\mathrm{R}^{1}$ had shown little effect on the conversion. Our gold catalyzed methodology for the cyclization of $\alpha, \beta$-acetylenic hydrazones seems to be advantageous compared to some of the relevant protocols developed in recent times. Most of these protocols suffer the stoichiometric use of reagents as in the case of electrophilic cyclization ${ }^{11}$ and tandem aminofluorination reactions. ${ }^{12}$ However, our protocol circumvents this limitation and entails only a very low catalytic loading of $\mathrm{AuCl}_{3}$. The structure of pyrazole products was established by routine spectroscopy techniques and compared with literature reports. ${ }^{11}$

Based on our previous observations, ${ }^{2 \mathrm{e}}$ a tentative mechanism is proposed for the formation of isoxazoles and pyrazoles (scheme 3). According to which, the gold metal centre activates the alkyne residue $\mathbf{I}$ to form the gold-alkyne $\pi$-complex II. Subsequent nucleophilic attack of the tethered nucleophile $\left(\mathrm{OH}, \mathrm{NHR}^{2}\right)$ leads to the cyclized intermediate III. Proto-deauration of intermediate III results in the formation of the product IV.

\subsection{Cytotoxicity}

Ten compounds of isoxazoles ( $\mathbf{3 a}, \mathbf{3 f}-\mathbf{3 j}, \mathbf{3 l}, \mathbf{3 m}, \mathbf{3 o}$ and $\mathbf{3 q})$ and pyrazoles $(\mathbf{5} \mathbf{a}-\mathbf{5 j})$ were selected to evaluate the cytotoxic potential against COLO320 cancer cell lines. The cytotoxic results were compared with reference drug cyclophosphamide which showed $90 \%$ inhibition at a concentration of $156 \mu \mathrm{M}$. The tested compounds exhibited maximum cytotoxicity against COLO320 cells at a concentration of 200 to $50 \mu \mathrm{M}$. All concentrations used in the experiment could decrease the cell viability significantly $(\mathrm{P}<0.05)$ in a concentrationdependent manner. Cytotoxicity of each sample was expressed as $\mathrm{IC}_{50}$ value. The $\mathrm{IC}_{50}$ value is the concentration of test sample that causes $50 \%$ inhibition of cell growth averaged from three replicate experiments (table 3). Analysis of the screening data revealed that isoxazole series $\left(\mathbf{3 a}-\mathbf{3 q}, \mathrm{IC}_{50}=38.9\right.$ to $\left.49.6 \mu \mathrm{M}\right)$ exhibited better activity compared to the pyrazole series $\left(\mathbf{5 a}-\mathbf{5} \mathbf{j}, \mathrm{IC}_{50}=50.8\right.$ to $\left.55.9 \mu \mathrm{M}\right)$. Among the tested series, isoxazole $\mathbf{3 h}$ possessing 6-MeO-2-naphthyl group emerged as the best active with an $\mathrm{IC}_{50}$ of 38.9 $\mu \mathrm{M}$ and this could be ascribed to the increased size and lipophilicity offered by the $\beta$-naphthyl residue. To our surprise, compound with a propyl chain $\mathbf{( 3 q}, \mathrm{IC}_{50}=$ $40.1 \mu \mathrm{M})$ emerged as the second most active among the screened compounds. The compound devoid of any substitution at the $\mathrm{C} 5$ position $\left(\mathbf{3 l}, \mathrm{IC}_{50}=43.9 \mu \mathrm{M}\right)$

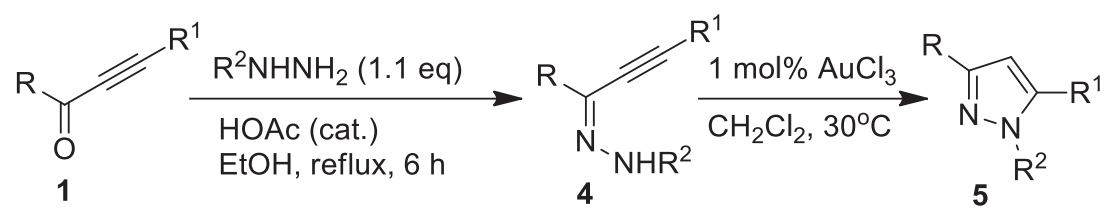

Scheme 2. Synthesis of pyrazoles. 


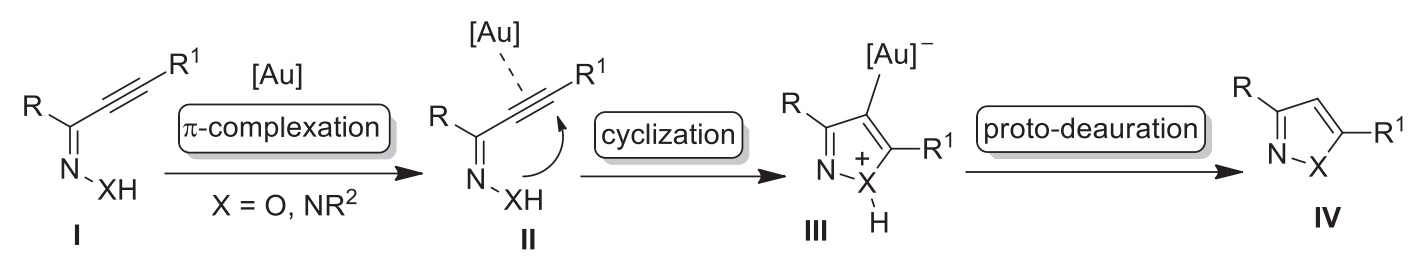

Scheme 3. Plausible mechanism for the formation of isoxazoles and pyrazoles.

Table 3. $\mathrm{IC}_{50}$ and FEB values of isoxazoles 3 and pyrazoles 5.

\begin{tabular}{lccc}
\hline Entry & Compound & $\mathrm{IC}_{50}(\mu \mathrm{M})$ & FEB $(\mathrm{kcal} / \mathrm{moL})^{\mathrm{a}}$ \\
\hline 1 & $\mathbf{3 a}$ & 45.4 & -6.43 \\
2 & $\mathbf{3 f}$ & 49.6 & -8.03 \\
3 & $\mathbf{3 g}$ & 46.9 & -7.74 \\
4 & $\mathbf{3 h}$ & 38.9 & -9.54 \\
5 & $\mathbf{3 i}$ & 46.2 & -6.58 \\
6 & $\mathbf{3 j}$ & 46.4 & -7.14 \\
7 & $\mathbf{3 l}$ & 43.9 & -5.72 \\
8 & $\mathbf{3 m}$ & 47.3 & -7.85 \\
9 & $\mathbf{3 o}$ & 45.0 & -6.21 \\
10 & $\mathbf{3 q}$ & 40.1 & -9.02 \\
11 & $\mathbf{5 a}$ & 52.5 & -6.72 \\
12 & $\mathbf{5 b}$ & 53.5 & -7.05 \\
13 & $\mathbf{5 c}$ & 52.8 & -6.97 \\
14 & $\mathbf{5 d}$ & 50.8 & -6.05 \\
15 & $\mathbf{5 e}$ & 51.9 & -6.62 \\
16 & $\mathbf{5 f}$ & 54.8 & -8.10 \\
17 & $\mathbf{5 g}$ & 52.3 & -6.73 \\
18 & $\mathbf{5 h}$ & 53.9 & -7.22 \\
19 & $\mathbf{5 i}$ & 55.9 & -8.26 \\
20 & $\mathbf{5 j}$ & 53.4 & -7.03 \\
\hline
\end{tabular}

${ }^{\mathrm{a}}$ Free energy of binding calculated using Autodock 4.

${ }^{\mathrm{b}}$ Cyclophosphamide was used as the standard for cytotoxic studies which showed $90 \%$ inhibition $(156 \mu \mathrm{M})$.

also demonstrated significant cytotoxicity. Other compounds of the isoxazole series exhibited comparable inhibitory potencies. However, compound $\mathbf{3 f}$ having $o$ cyanophenyl showed poor activity $\left(\mathrm{IC}_{50}=49.6 \mu \mathrm{M}\right)$ among the isoxazole series suggesting that the nitrile function at those sites is not tolerated. Assessment of the pyrazole series revealed that compound with a pentyl chain $\left(\mathbf{5 d}, \mathrm{IC}_{50}=50.8 \mu \mathrm{M}\right)$ exhibited good activity compared to other compounds in the same series.

\subsection{Molecular docking}

Aurora-A is a family of serine/threonine kinases that are involved in the correct centrosome maturation and separation. Aurora-A kinases have attracted significant attention for small molecule inhibition because its elevation may play a vital role in the support of tumour progression which is evident by its high expression in many tumour cells. Moreover, inhibition studies of Aurora-A kinase expression in the cells induce the apoptosis and subsequently results in the cell death. ${ }^{13}$ Twenty compounds (3a, 3f-3j, 3l, 3m, 3o, 3q and 5a-5j) were subjected to molecular docking studies using the AutoDock Tools (ADT) version 1.5.6 and AutoDock version 4.2.5.1 docking program ${ }^{14}$ to investigate the potential binding mode of inhibitors with Aurora-A kinase receptor (PDB ID: 3P9J). To start with, the reproducibility of docking calculations was verified by extracting the bound ligand from the complexes and submitted for one-ligand run calculation. This reproduced top scoring conformation falling within rootmean-square deviation (RMSD) value of 0.50 to 0.61 $\AA$ with bound X-ray conformation for 3P9J, suggesting this method is valid enough to be used for docking studies of other compounds (figure S1). Docking of different ligands to Aurora-A kinase was performed using AutoDock, following the same protocol used in the validation study (figure S2). All dockings were taken into 2.5 million energy evaluations and were performed for each of the test molecules. Docked ligand conformations were analyzed in terms of energy, hydrogen bonding and hydrophobic interaction between ligand and receptor protein Aurora-A. Detailed analyses of the ligand-receptor interactions were carried out and final coordinates of the ligand and receptor were saved. PyMOL software was used for display of the receptor with the ligand binding site. From the docking scores, the free energy of binding (FEB) of all compounds were calculated (table 3). The results revealed that the compounds are efficiently bound with the $3 \mathrm{P} 9 \mathrm{~J}$ receptor and exhibit free energy of binding (FEB) from -4.53 to -9.54 $\mathrm{kcal} / \mathrm{mol}$. All the docked compounds fit in the active site of 3P9J receptor and interact with the nine amino acids namely LEU-139, VAL-147, LYS-162, LEU-194, LEU-210, GLU-211, TYR-212, ALA-213 and LEU263. Among all the compounds docked, compound $\mathbf{3 h}$, although not significant, but exhibits highest binding energy of $-9.54 \mathrm{kcal} / \mathrm{mol}$ (figure S3). In compound $\mathbf{3 h}$, the isoxazole ring oxygen interacts with $\mathrm{N}-\mathrm{H}$ of the ALA-213 and forms a hydrogen bond with the bond length of $2.1 \AA$. Also, methoxy oxygen interacts with N$\mathrm{H}$ of the LYS-162 and forms a hydrogen bond with the bond length of $2.0 \AA$. Furthermore, the polar interaction 
between isoxazole nitrogen and $\mathrm{C}=\mathrm{O}$ of the ALA-213 occurs in the distance of $2.8 \AA$. Importantly, $\pi$-cationic interaction results between naphthyl ring and $\left(\mathrm{NH}_{3}\right)^{+}$of LYS-162. It is noteworthy to mention that the naphthyl ring fits in the lipophilic pocket of the active site consist of five amino acids namely, LEU-139, VAL-147, LUE-194, LEU-210 and LEU-263.

\section{Conclusions}

In summary, a general strategy that supports the synthesis of both isoxazoles and pyrazole involving gold-catalyzed cycloisomerization of $\alpha, \beta$-acetylenic oximes/hydrazones has been developed. From a synthetic chemist perspective, the key features of our protocol include low catalyst loading, short reaction time and an overall satisfactory chemical yields. Cytotoxic evaluation of these compounds against COLO320 cells had shown activity with the $\mathrm{IC}_{50}$ values ranging between 38.9 and $55.9 \mu \mathrm{M}$. Compound $\mathbf{3 h}$ emerged as the most active $\left(\mathrm{IC}_{50}=38.9 \mu \mathrm{M}\right)$ amongst the tested series. Molecular docking of compound $\mathbf{3 h}$ into Aurora-A kinase receptor exhibited the largest binding energy ($9.54 \mathrm{kcal} / \mathrm{mol}$ ) compared to other compounds and thus supports the in vitro results. Further investigations on application of this methodology towards natural product synthesis are in progress.

\section{Supplementary Information}

Docking poses of all the screened compounds and copy of IR, ${ }^{1} \mathrm{H}$ NMR, ${ }^{13} \mathrm{C}$ NMR and mass of compounds $\mathbf{3 m}$ and $\mathbf{5 b}$ are available at www.ias.ac.in/chemsci.

\section{Acknowledgements}

C.P. gratefully acknowledges the financial support of the Department of Science \& Technology (DST), India for providing INSPIRE faculty award. C.P. also thanks Dr. Vijayamohanan K. Pillai and Dr. D. Jeyakumar, CSIR-CECRI for infrastructure facilities.

\section{References}

1. (a) Arcadi A 2008 Chem. Rev. 108 3266; (b) Hashmi A S K and Rudolph M 2008 Chem. Soc. Rev. 37 1766; (c) Zhang Y, Luo T and Yang Z 2014 Nat. Prod. Rev. 31 489; (d) Fürstner A 2014 Acc. Chem. Res. 47 925; (e) Hashmi A S K and Bührle 2010 Aldrichim. Acta. 43 27; (f) Wegner H A and Auzias M 2011 Angew. Chem. Int. Ed. 50 8236; (g) Patil N 2012 Chem. Asian. J. 7 2186; (h) Inamdar S M, Konala A and Patil N T 2014 Chem. Commun. 50 15124; (i) Bandini M 2011 Chem. Soc. Rev. 40 1358; (j) Patil N T and Singh V 2011 J. Organomet. Chem. 696 419; (k) Patil N T, Kavthe R D and Shinde V S 2012 Tetrahedron 68 8079; (1) Corma A, Leyva-Pérez A and Sabater M J 2011 Chem. Rev. 111 1657; (m) Patil N T 2013 Curr. Sci. 1041671

2. (a) Praveen C, Sagayaraj Y W and Perumal P T 2009 Tetrahedron Lett. 50 644; (b) Praveen C, Karthikeyan K and Perumal P T 2009 Tetrahedron 65 9244; (c) Praveen C, Kiruthiga P and Perumal P T 2009 Synlett 1990; (d) Praveen C, Jegatheesan S and Perumal P T 2009 Synlett 2795; (e) Praveen C, Kalyanasundaram A and Perumal P T 2010 Synlett 777; (f) Praveen C and Perumal P T 2011 Synlett 521; (g) Praveen C, Ayyanar A and Perumal P T 2011 Bioorg. Med. Chem. Lett. 21 4170; (h) Praveen C, Perumal P T 2016 Chin. J. Catal. 37 (DOI: 10.1016/S1872-2067(15)60994-9)

3. (a) Teresa M V D and Melo P e 2005 Curr. Org. Chem. 9 925; (b) Fustero S, Simón-Fuentes A and Sanz-Cervera J F 2009 Org. Prep. Proc. Int. 41 253; (c) Kumar V, Kaur K, Gupta G K and Sharma A K 2013 Eur. J. Med. Chem. 69 735; (d) Michelot D and Melendez-Howell L M 2003 Mycol. Res. 107 131; (e) Regoli D and Barabé J 1980 Pharmacol. Rev. 32 1; (f) Sperry J and Wright D 2005 Curr. Opin. Drug Discovery Dev. 8 723; (g) Talley J J, Brown D L, Carter J S, Graneto M J, Koboldt C M, Masferrer J L, Perkins W E, Rogers R S, Shaffer A F, Zhang Y Y, Zweifel B S and Seibert K J 2000 J. Med. Chem. $\mathbf{4 3} 775$

4. Margaretha P 2010 Science of Synthesis 1109

5. (a) Deng X and Mani N S 2008 J. Org. Chem. 73 2412; (b) Meng L, Lorsbach B A, Sparks T C, Fettinger J C and Kurth M J 2010 J. Comb. Chem. 12 129; (c) Grotjahn D B, Van S, Combs D, Lev D A, Schneider C, Rideout M, Meyer C, Hernandez G and Majorado L 2002 J. Org. Chem. 679200

6. (a) Alley M C, Scudiero D A, Monks A, Hursey M L, Czerwinski M J, Fine D L, Abbott J G M, Shoemaker R H and Boyd M R 1988 Cancer Res. 48 589; (b) Mossman T 1983 J. Immunol. Methods 65 55; (c) Wallace A C, Lasowski R A and Thornton J M 1995 Protein Eng. 8127

7. (a) Waldo J P and Larock R C 2005 Org. Lett. 7 5203; (b) Waldo J P, Mehta S, Neuenswander B, Lushington G H and Larock R C 2008 J. Comb. Chem. 10 658; (c) Waldo J P and Larock R C 2007 J. Org. Chem. 72 9643

8. Short K M and Ziegler Jr. C B 1993 Tetrahedron Lett. 3475

9. (a) Balakrishnan B, Praveen C, Seshadri P R and Perumal P T 2013 Acta Cryst. E69 o597; (b) Balakrishnan B, Praveen C, Seshadri P R and Perumal P T 2011 Acta Cryst. E67 o1575

10. Aldeco-Pérez E J, Álvarez-Toledano C, Toscano A, García-Estrada J G and Penieres-carrillo J G 2008 Tetrahedron Lett. 492942

11. (a) Zora M, Kivrak A and Yazici C $2011 \mathrm{~J}$. Org. Chem. 76 6726; (b) Zora M and Kivrak A 2011 J. Org. Chem. 769379 
12. Qian J, Liu Y, Zhu J, Jiang B and Xu Z 2011 Org. Lett. 134220

13. (a) Keen N and Taylor S 2004 Nat. Rev. Cancer 4 927; (b) Prime M E, Courtney S M, Brookfield F A, Marston R W, Walker V, Warne J, Boyd A E, Kairies N A, von der Saal W, Limberg A, Georges G, Engh R A,
Goller B, Rueger P and Rueth M 2011 J. Med. Chem. 54 312

14. (a) Morris G M, Huey R, Lindstrom W, Sanner M F, Belew R K, Goodsell D S and Olson A J 2009 J. Comput. Chem. 30 2785; (b) Sanner M F 1999 J. Mol. Graphics Mod. 1757 